\title{
The Everyday Life Information Behaviour of Immigrants: A Case of Bangladeshi Women
}

\author{
Nafiz Zaman Shuva, Western University, Canada
}

Keywords: barriers to information access; Canada; everyday life Information behaviour of immigrants; sources of information; women immigrants

Publication Type: poster

\begin{abstract}
Immigrants need information at various stages of their settlement. For immigrants, lack of timely relevant information before and after arrival may lead to social isolation, depression, and dissatisfaction with their lives in their host countries. Several studies (e.g., Caidi, Allard, \& Quirke, 2010; Esses \& Meadianu, 2012) recognize the importance of timely information for efficient settlement of immigrants. Employing a qualitative research approach, I conducted 22 semi-structured interviews to acquire information on various aspects of Bangladeshi immigrant women's lives including everyday life information behaviour in Bangladesh and in Canada, their settlement information needs, political participation in Canada, public library use, and awareness about their rights in Canada.

In this poster, I present the everyday life information behaviour of Bangladeshi women immigrants who participated in this study. It is evident in my study that migration has substantially affected the everyday information behaviour of Bangladeshi women immigrants. Quite a few participants clearly indicated that the everyday life information behaviour in Canada compared to Bangladesh is completely different. Based on the results of the current study, I have identified that local systems, family responsibilities, language, education, dependency on family members, unemployment/intention to change jobs, and social interactions heavily affect immigrants' everyday life information behaviour in Canada. For example, Bangladeshi immigrants who participated in the study did not look for weather and transportation updates when they were in Bangladesh, but after moving to Canada or countries where the local systems support the real-time update of weather and transport, they always require it. Moreover, due to sociocultural patterns, immigrant women hailing from Bangladesh had less administrative responsibilities and worries compared to here in Canada. Furthermore, many immigrants were not regular users of the internet when they were in Bangladesh, but after moving to Canada, they have adopted frequent use of it.

It is further evident in my study that the information needs reported by Bangladeshi immigrant women are very much connected with their everyday life practices. The study found that immigrants create their own small world (Chatman, 1991) in their host countries and seek information and help from people in their small world. The study also found the high dependency of Bangladeshi immigrant women on family members and friends for satisfying their day-to-day information needs. It is also evident in the study that Savolainen's (1995) Everyday Life Information Seeking (ELIS) model may not be suitable to capture the information practices of various immigrant groups (especially newcomers) due to migrational
\end{abstract}

The International Journal of Information, Diversity, \& Inclusion, 2(1-2), 2018

ISSN 2574-3430, publish.lib.umd.edu/IJIDI/ 
effects. Immigrants may have a completely different set of everyday life information needs compared to their early life in their home country before migrating to a new country. They may have to compromise their long-practiced habits due to several factors including unemployment and depression.

Based on the results of my pilot study, I propose an Everyday Life Information Behaviour Model to capture the everyday life information behaviour of immigrants and to posit the connection between everyday life information behaviour of immigrants and their social integration and settlement. The model illustrates core factors affecting everyday life information needs as well as the core everyday life information needs of Bangladeshi immigrant women. These factors are shown to feed into levels of information seeking anxiety, to support or respond to certain kinds of information grounds, and to construct or mediate certain barriers to information access. Furthermore, all of these factors are shown to suggest a continuum of social integration for my participants.

\section{The following references were consulted in the preparation of the abstract and poster.}

Caidi, N., Allard, D., \& Quirke, L. (2010). Information practices of immigrants. Annual Review of Information Science and Technology, 44(1), 491-531.

Chatman, E. A. (1991). Life in a small world: Applicability of gratification theory to information seeking behavior. Journal of the American Society for Information Science, 42(6), 438449.

Esses, V.M. \& Medianu, S. (2012). Integration barriers and information as a solution: Report based on literature covering 2005-2011 inclusive. Retrieved from http://p2pcanada.ca/wp-content/uploads/2012/08/Integration-Barriers-andInfomation-as-a-Solution.pdf

Savolainen, R. (1995). Everyday life information seeking: Approaching information seeking in the context of way of life. Library \& Information Science Research, 17(3), 259-94.

Nafiz Zaman Shuva (nshuva@uwo.ca) is a Ph.D. Candidate in the Faculty of Information and Media Studies at Western University, London, Ontario, Canada. He is an assistant professor (on study leave) in the Department of Information Science and Library Management at the University of Dhaka, Bangladesh. Nafiz holds two Masters in Library and Information Scienceone from the University of Dhaka and other from the three European universities in Norway, Estonia, and Italy (Erasmus Mundus program). Nafiz's doctoral study seeks to understand the transitional information practices of immigrants in Canada and the role of information in their Canadian lives, looking in particular at the information practices that occur between pre-arrival and after arrival information needs and seeking related to settlement into Canada. Nafiz is the founder president of the Bangladesh Association of Young Researchers (BAYR) and is one of the ASIS\&T (SIG-III) international paper contest winners of 2004. His research revolves around information practices, the role of information in society, digital inclusion, digital libraries, public libraries, and open access. 